\title{
ROLE OF INTERGRANULAR FILMS IN TOUGHENED CERAMICS
}

\author{
P. F. Becherl, E. Y. Sun 1,2 , C. H. Hsueh, ${ }^{1}$ G. S. Painter 1, and K. L. Morel \\ 1. Metals and Ceramics Division, Oak Ridge National Laboratory, Oak Ridge, TN \\ 2. Now with United Technologies Research Center, Hartford, CT
}

Keywords: Self-reinforcement, toughness, silicon nitride, interface debonding, intergranular films, cluster calculations, microstructure

\begin{abstract}
Self-reinforced silicon nitride ceramics rely the generation of elongated grains that act as reinforcing elements to gain increases in fracture toughness. However, the size and number of the reinforcing grains must be controlled, along with the matrix grain size, to optimize the fracture toughness and strength. Furthermore, the toughening processes of crack bridging are dependent upon retention of these reinforcing grains during crack extension by an interfacial debonding process. Both the debonding process and the resultant toughening effects are found to be influenced by the composition of the sintering aids which typical are incorporated into the amorphous intergranular films found in these ceramics. Specifically, it is shown that the interface between the intergranular glass and the reinforcing grains is strengthened in the presence of an epitaxial SiAlON layer. In addition, the interface strength increases with the $\mathrm{Al}$ and 0 content of the SiAlON layer. Micromechanics modeling indicates that stresses associated with thermal expansion mismatch are a secondary factor in interfacial debonding in these specific systems. On the other hand, first principles atomic cluster calculations reveal that the debonding behavior is consistent with the formation of strong Si-0 and Al-O bonds across the glasscrystalline interface.
\end{abstract}

\section{Background}

As a class of materials, ceramics present an unusually complex set of both intellectual and technological challenges. One of the key issues has been the need to make ceramics tougher by devising approaches to increase the energy required to grow cracks. On the other hand, ceramics, such as silicon nitride, continue to find important and demanding applications including high performance bearings, turbocharger rotors, fuel ignitors and machine tool inserts. The most recent important milestones achieved include the incorporation of silicon nitride ceramic as (1) hot section components produced by AlliedSignal for aircraft and industrial auxiliary turbo-power units and various components for aircraft turbine engines $\mathbf{1}$ and (2) valves in selected automotive diesel engines by Daimler-Benz.2 Even with these successes, ceramics that have greater toughness and strength will be necessary to meet the demands of potential future markets for advanced ceramics.

In the 1980 s, researchers showed that very strong microscopic single crystal whiskers that were $<2$ microns in diameter $(-1 / 50$ th the diameter of a human hair) and $<30$ microns in length could provide a very potent contribution in ceramics. 3 These studies also described both the responsible toughening mechanisms and how various materials characteristics and properties controlled the toughening effects. $\mathbf{3 , 4}$ The potential toughening effects that can be achieved in the presence of microscopic reinforcements is not limited to the incorporation of strong whiskers. In the past, whisker-like grains have been observed in a wide variety of ceramics so it seemed natural that it might be possible to also toughen 
ceramics where rod- or whisker-like grains were generated. ${ }^{4}$ Initial success along these lines was achieved in silicon nitride.5

One first needs to determine how these elongated grains can act as reinforcements. Figure 1 shows a large elongated silicon nitride grain that is still intact and bridges the crack $\sim 20$ microns behind the tip of the crack. This grain holds the crack together and requires much greater applied strain energy to extend the crack. Note that an amorphous (white) network surrounds all the silicon nitride (gray) grains. A key feature here is the breaking of the bond between the elongated bridging grain and the surrounding amorphous network along a portion the grain-glass interface. This interface fracture/debonding has allowed the crack tip to pass without cutting through the reinforcement. This illustrates the key mechanisms required to toughen this ceramic: (1) the formation of strong elongated grains and (2) debonding along the interface between these grains and the intergranular amorphous network to form a crack bridging reinforcement.

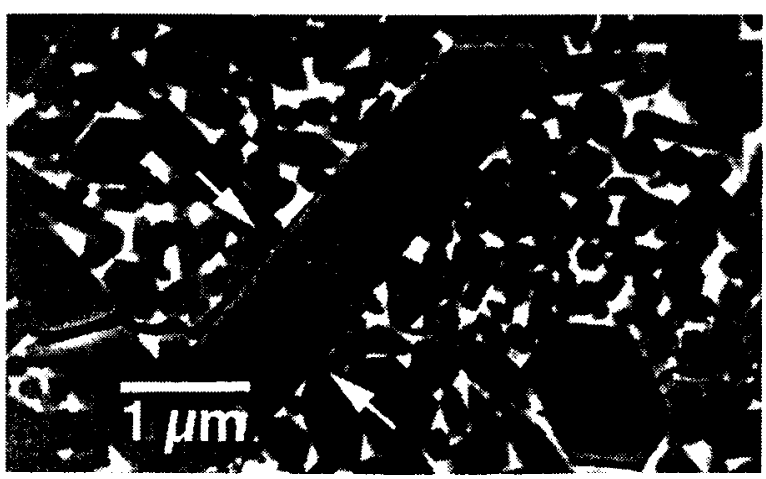

Figure 1. A larger elongated grain in a silicon nitride ceramic bridges across a crack behind its tip. Note the interface between the grain and the matrix has separated/debonded along a portion of the grain's length (arrows). A glass network (white) surrounds all the silicon nitride grains as well.

\section{Role of Microstructure}

In using these microscopic reinforcements, we need to ask what is needed in terms of these microscopic reinforcements. First, the length of the reinforcing grain must meet the conditions for efficient transfer of load to the reinforcement when the crack passes it (e.g., the length to diameter ratio must be $>4: 1$ based on the mechanics of the silicon nitride system). Second, frictional motion of the debonded reinforcement against the matrix is a significant toughening contribution. This is enhanced with increase in the reinforcement's diameter, as well as the length of the debonded interface over which frictional sliding occurs. The frictional contribution to the toughening process depends not on the size but also on the number fraction of reinforcements. $\mathbf{6 , 7}$ Theoretically the toughness obtained with a given number of one micron diameter reinforcements per unit volume could also be achieved by using twice as many half micron diameter reinforcements.

One can see the effects of reinforcing grains on the fracture toughness of silicon nitride by carefully changing the microstructure of the ceramics in which the amount and composition of the intergranular glass phase were kept constant.* The number and size of the reinforcing grains generated during the sintering of silicon nitride powder compacts was controlled either by the silicon nitride powder used and the sintering temperature and time, 
or by the addition of microscopic rice-shaped $\beta-\mathrm{Si}_{3} \mathrm{~N}_{4}$ seeds. ${ }^{9}$,a By characterizing the resistance to the growth of small cracks in these ceramics, one can assess two very important toughening features: (1) the maximum toughness achieved and (2) how rapidly the toughness/resistance increases as the crack grows. In ceramics, we are most often concerned with the role of small cracks (i.e., 10's of microns in length) that result in failure. Thus, we are searching for materials not only with high fracture toughness but also for toughening effects that increase quickly with very small crack extensions. One observes that the silicon nitride with only fine, equiaxed grains, Figure 2 bottom micrograph, has little resistance to the growth of a crack regardless of the crack length. The lack of toughness is not surprising considering the absence of elongated reinforcing grains; note also the low fracture strength in this material. When larger elongated grains are generated but with little control of their number and size (Figure 2, middle micrograph), there is a modest toughening effect which rises rapidly for even small amounts of crack growth and the fracture strength increases to $850 \mathrm{MPa}$.

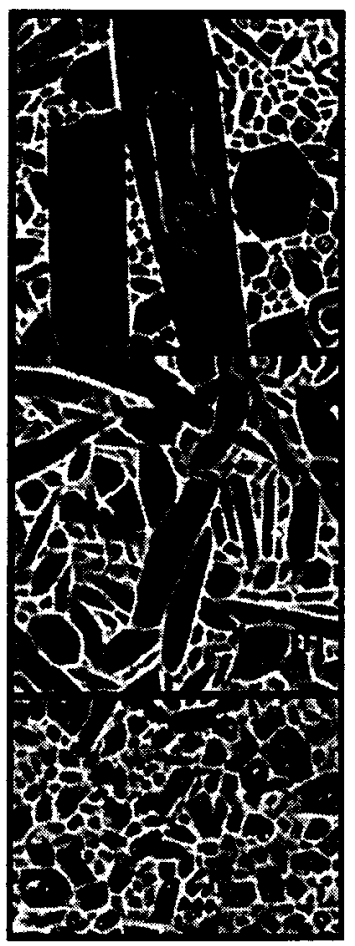

Figure 2. The fracture resistance curves reveal that the toughness increases with the controlled introduction of reinforcing grains. The ceramic with no reinforcing grains (lower micrograph) exhibits a toughness of $3-3.5 \mathrm{MPa} \sqrt{\mathrm{m}}$. The ceramic with the uncontrolled introduction of reinforcing grains (middle micrograph) exhibits a toughness of 6 - 6.5 MPa $\sqrt{\mathrm{m}}$. With selective generation of reinforcing grains (upper micrograph) a toughness of $\sim 11 \mathrm{MPa} \sqrt{\mathrm{m}}$ is obtained.

If instead we control the generation of larger elongated grains in a fine grained matrix (Figure 2, upper micrograph), a very high fracture toughness, representing a nearly fourfold increase, is achieved characterized by a rapid rise in resistance as a small crack attempts to grow. This combination results in a very high strength (up to $1400 \mathrm{MPa}$ )

a These samples were fabricated at the NIRI-Nagoya ceramics laboratory by Dr. K. P. Plucknett, who was an ORNL Postdoctoral Fellow at the time. His research activitives there with Drs. K. Hirao and M. Brito were also supported by a Japanese Agency for Industrial Science and Technology Fellowship. 
material that is very resistant to fracture. These results are a clear demonstration that simply introducing larger elongated grains in the matrix is not sufficient to obtain the desired toughening effects. These observations emphasize that one must control the size and number of elongated grains in self-reinforced ceramics, e.g., silicon nitride.

\section{Influence of Interface Characteristics}

As pointed out in Figure 1, these microscopic reinforcements only work when interfacial debonding process occurs and allows the reinforcement to survive as a growing crack reaches and passes it. Thus, the glass network appears to play an important role in the debonding and toughening processes in silicon nitride ceramics. These intergranular films result from the reaction between the chemical additives used to promote densification and the native silicon-oxygen species on the silicon nitride powders during sintering. The resultant glass formation serves as a viscous media for the growth of the elongated grains, as well as promoting the formation of a dense silicon nitride. Historically, researchers have used different amounts and types of sintering additives; thus, one might suspect that the resultant composition of this glass phase might influence the ease of interfacial debonding and, thus, the toughening effects.

An indentation cracking method was used to examine interfacial debonding involving such microscopic reinforcements employing silicon nitride whiskers dispersed in oxynitride glasses.10 The technique allows one to systematically determine the length over which the interface is debonded $\left(l_{\mathrm{db}}\right)$ [created when the crack is deflected at and extends up the interface] for a variety of angles $(\theta)$ of incidence between the crack plane and the whisker's prism surface. Because it is difficult to cause a crack to deflect up out of plane, cracks will deflect up along only the weaker interfaces when the angle of incidence is high. Thus, the interface strength (and energy to debond the interface) will decrease as the angle for the onset of debonding $\left(\theta_{\text {crit }}\right)$ increases.

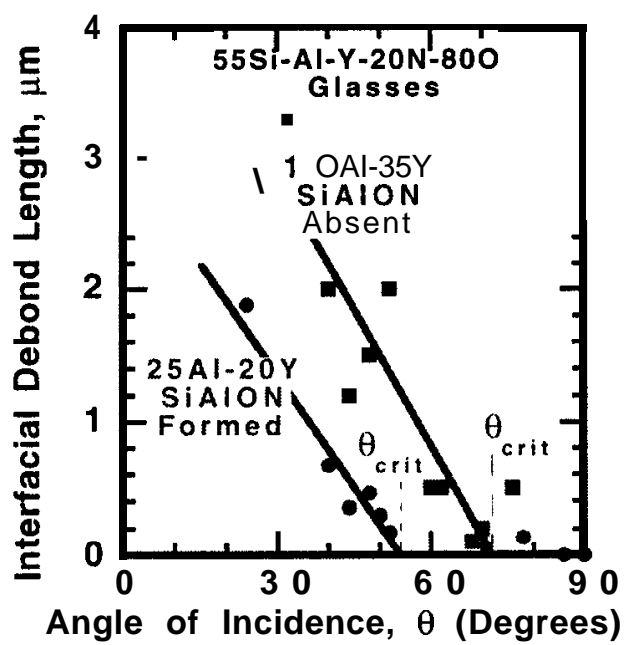

(a)

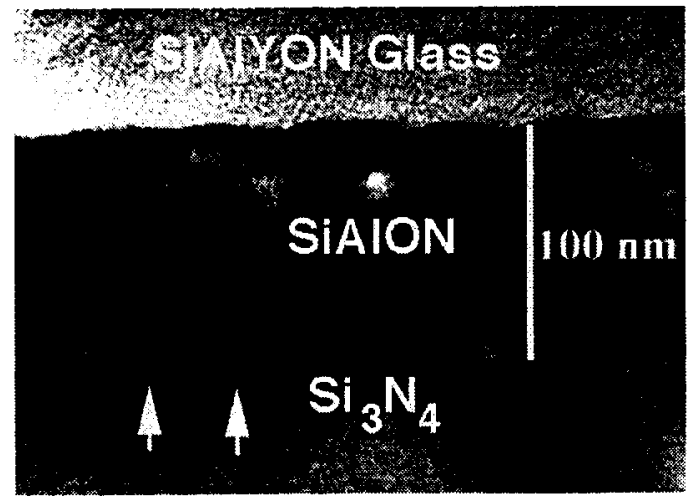

(b)

Figure 3. Observations of the conditions for the onset of interfacial debonding reveal that the composition of the Si-Al-Y oxynitride glass (composition in equivalent \%, Eq. \%) altered the angle for the onset for debonding (a), hence the interface strength. In the case of the stronger interface (smaller $\theta_{\text {crit }}$ value), an epitaxial SiAlON layer formed on the silicon nitride (b). The interface between these two crystalline phases exhibited a low density of misfit dislocations (see arrows). 
Let us examine, the debonding conditions associated with $\mathrm{Si}-\mathrm{Al}-\mathrm{Y}-\mathrm{O}-\mathrm{N}$ glasses as these form, in silicon nitride ceramics from the often used yttria plus alumina sintering additives. Here it was found that simply changing the composition of the Si-Y-Al oxynitride glass modified the interfacial debonding conditions significantly. By decreasing the ratio of $\mathrm{Al}$ to $\mathrm{Y}$ in the glass, the interfacial strength was reduced as indicated by the increase in the critical angle for the onset of debonding $\left(\theta_{\text {crit }}\right)$, Figure 3. Subsequent transmission electron microscopy studies showed that the sample with the highest Al:Y ratio glass revealed the presence of an epitaxial $\mathrm{Si}_{6-\mathrm{z}} \mathrm{Al}_{2} \mathrm{O}_{2} \mathrm{~N}_{8-\mathrm{z}}$ (or $\mathrm{SiAlON}$ ) layer formed on the $\mathrm{Si}_{3} \mathrm{~N}_{4}$ whiskers, Table I.10 This SiAlON phase is isostructural with $\mathrm{Si}_{3} \mathrm{~N}_{4}$ and involves a small dilation of the lattice as $\mathrm{Al}$ and 0 are substituted for $\mathrm{Si}$ and $\mathrm{N}$. On the other hand for glass with the lowest Al:Y ratio, the weak interface consisted only of the glass in contact with the $\mathrm{Si}_{3} \mathrm{~N}_{4}$ whisker.

Table I. Summary of the critical interfacial debond angles for the $\beta$-Si3 $\mathrm{N}_{4} /$ oxynitride glass systems.

\begin{tabular}{|c|c|c|c|}
\hline Sample & $\begin{array}{l}\text { Critical Debond } \\
\text { Angle, Degrees }\end{array}$ & $\begin{array}{l}\text { Residual Radial } \\
\text { Stress Imposed on } \\
\text { Interface, } \mathrm{MPa}^{\mathrm{b}}\end{array}$ & $\begin{array}{c}\mathrm{z}-\mathrm{V} \text { alue of Epitaxial } \\
\mathrm{Si}{ }_{6} \mathrm{zAl}_{\mathrm{Z}} \mathrm{O}_{\mathrm{z}} \mathrm{N} 8-\mathrm{z} \\
\text { Layer }\end{array}$ \\
\hline \multicolumn{4}{|c|}{$\beta-\mathrm{Si}_{3} \mathrm{~N}_{4}$ Whiskers in Oxynitride Glass Matrix } \\
\hline \multicolumn{4}{|c|}{ Composition, Eq. \% } \\
\hline $55 \mathrm{Si} 25 \mathrm{Al} 20 \mathrm{Y} 20 \mathrm{~N} 80 \mathrm{O}$ & -55 & $\sim 350$ & 1.0 \\
\hline $\begin{array}{c}5 \text { Si10Al35Y20N80O } \\
\text { w/o SiAlON } \\
\text { w SiAlON }\end{array}$ & $\begin{array}{l}\sim 73 \\
-50\end{array}$ & $\begin{array}{r}\sim 530 \\
\sim 530 \\
\end{array}$ & $\begin{array}{c}0 \\
\text { None present } \\
0.15 \\
\end{array}$ \\
\hline 57Si0A143La20N80O & $\sim 72$ & $\sim 590$ & None \\
\hline 46Si27Al27La27N730 & -50 & $\sim 555$ & $1.6-2.0$ \\
\hline 41 Si30A129Yb23N770 & -56 & $\sim 455$ & $1.6-2.0$ \\
\hline \multicolumn{4}{|c|}{ Self-Reinforced $\beta$-Si3 $N_{4}$ with Amorphous Intergranular Film } \\
\hline \multicolumn{4}{|c|}{ Additives, wt. \% Yttria/Alumina } \\
\hline 6.2511 .0 & $\sim 75$ & & 0.01 \\
\hline $5.0 / 2.0$ & -70 & & 0.03 \\
\hline $4.0 / 2.8$ & -60 & & 0.06 \\
\hline
\end{tabular}

This was the first such evidence that the composition of the glass phase can have a substantial impact on the strength of the interface with the reinforcing grains in a ceramic. In the presence of an epitaxial SiAlON layer, similar types of $\mathrm{Si}-\mathrm{N}, \mathrm{Si}-0$, and $\mathrm{Al}-\mathrm{O}$ bonding are present in both the glass and the epitaxial $\mathrm{Si}_{6-z} \mathrm{Al}_{2} \mathrm{O}_{2} \mathrm{~N}_{8-\mathrm{z}}$ layer. Thus, it seemed plausible that the interface strength might be altered by the composition of the epitaxial $\mathrm{Si} 6-\mathrm{z} \mathrm{Al}_{\mathrm{Z}} \mathrm{O}_{\mathrm{Z}} \mathrm{N}_{8-\mathrm{z}}$ layer formed on the $\mathrm{Si}_{3} \mathrm{~N}_{4}$ whiskers or grains (i.e., there might be a transition in interface strength with the $\mathrm{z}$-value of the SiAlON layer). Additional experiments reveal that the strength of the interfaces decreases (i.e., $\theta_{\text {crit }}$ increases) as the $\mathrm{Al}$ and 0 content (e.g., $\mathrm{z}$ values) of the epitaxial $\mathrm{Si}_{6-\mathrm{Z}} \mathrm{Al}_{2} \mathrm{O}_{2} \mathrm{~N}_{8-\mathrm{Z}}$ layer on the $\mathrm{Si}_{3} \mathrm{~N}_{4}$ decreases, Table I.11,12 Similar response is seen when Lanthanum or Ytterbium are

b Calculated stress based on measured values of $\mathrm{Tg}$ and $\alpha$ but with $\mathrm{E}$ equal to $145 \mathrm{GPa}$ in all glasses. 
substituted for Yttrium in the SiAlRe oxynitride glass with a significant increase in the critical debond angle when an epitaxial SiAION layer forms on the silicon nitride. Interestingly, there is no correlation between the critical debond angle and the magnitude of compressive residual stress imposed on the interface by the glass matrix. Clearly, some factor other than the residual stress is dominating the debonding response for the whiskerglass system. Finally, we note that the there is a rapid reduction in the critical debonding angle with increase in the $\mathrm{Al}$ (and 0) content (z-value) of the epitaxial layer in both silicon nitride ceramics and the glasses containing dispersed whiskers.

Finally, one then had to address how the glass composition effected the toughness of the self-reinforced silicon nitride ceramics with identical microstructures. Again in collaboration with our colleagues at NIRI-Nagoya, self-reinforced silicon nitride ceramics, each with the same amount and size of larger elongated grains in a fine grained matrix and amount of intergranular glass were fabricated with specific yttria to alumina ratios. ${ }^{11}$ Analytical electron microscopy observations showed that (1) an epitaxial $\mathrm{Si}_{6-\mathrm{z}} \mathrm{Al}_{\mathrm{z}} \mathrm{O}_{\mathrm{z}} \mathrm{N}_{8-\mathrm{z}}$ layer was formed on the elongated reinforcing $\mathrm{Si}_{3} \mathrm{~N}_{4}$ grains in each ceramic and (2) the Al and 0 content (or z-value) of this layer decreased as the yttria to alumina ratio of the original additives increased. The observed toughening effect due to self-reinforcement increased very significantly with decrease in the $\mathrm{z}$-value of the epitaxial $\mathrm{Si}_{6-\mathrm{z}} \mathrm{Al}_{\mathbf{z}} \mathrm{O}_{\mathbf{z}} \mathrm{N}_{8-\mathrm{z}}$ layer formed in each of the $\mathrm{Si}_{3} \mathrm{~N}_{4}$ ceramics, Table II. Thus, changing the additive composition and, thus, enhancing the strength of the interface between the reinforcing grains and the glass network is a powerful method for tailoring the properties. With the exception of thick film resistors, few such graphic examples of the important positive contribution of an intergranular glass phase to the behavior of ceramics are known to exist.

Table II. The Steady-State Toughness of Self-Reinforced $\beta-\mathrm{Si}_{3} \mathrm{~N}_{4}$ Ceramics with Fixed Microstructure (See Figure 2, upper micrograph).

\begin{tabular}{|c|c|c|}
\hline $\begin{array}{c}\text { Additive Composition, wt. } \\
\%\end{array}$ & $\begin{array}{c}\text { z-Value of Epitaxial SiAlON } \\
\text { Layer }\end{array}$ & $\begin{array}{c}\text { Fracture loughness, } \\
\text { MPa } \sqrt{m}\end{array}$ \\
\hline $6.25 \mathrm{Y}_{2} \mathrm{O}_{3} / 1.0 \mathrm{Al}_{2} \mathrm{O}_{3}$ & 0.01 & 10.6 \\
\hline $5.0 \mathrm{Y}_{2} \mathrm{O}_{3} / 2.0 \mathrm{Al}_{2} \mathrm{O}_{3}$ & 0.03 & 8.8 \\
\hline $4.0 \mathrm{Y}_{3} \mathrm{O}_{3} / 2.8 \mathrm{Al}_{2} \mathrm{O}_{3}$ & 0.06 & 7.4 \\
\hline
\end{tabular}

\section{Atomistic Bonding at the Interface}

Naturally, one asks why does the composition of the interfacial region appear to alter the debonding conditions, especially as noted in the presence of an epitaxial SiAION layer on the $\mathrm{Si}_{3} \mathrm{~N}_{4}$ reinforcing grains. Earlier structure calculations showed that the substitution of $\mathrm{Al}$ and 0 into the lattice of $\beta-\mathrm{Si}_{3} \mathrm{~N}_{4}$ reduces the total overlap population (a measure of electron bond density contributed from each constituent atom) and appears to result in a reduction of the mechanical properties of $\beta-\mathrm{Si}_{6-z} \mathrm{Al}_{2} \mathrm{O}_{2} \mathrm{~N}_{8-\mathrm{z}}$ versus $\beta-\mathrm{Si}_{3} \mathrm{~N}_{4} \cdot{ }^{13}$ More recently, crystal orbital-based calculations have assessed the bonding of $\mathrm{Al}$ and 0 to the surfaces of $\beta-\mathrm{Si}_{3} \mathrm{~N}_{4}$ and suggested stronger bonding of these elements to the prism faces as compared to the basal surface. ${ }^{\mathbf{1 4}}$ However, these studies do not specifically address the differences in interface strengths observed here. Atomic-scale calculations based on cluster models are currently being used to evaluate the effects of cation and anion substitution on the local bonding at the interfaces. 12,15 Initially, the binding energies within tetrahedra with silicon or aluminum embedded in the center were addressed, Figure 4. Note that tetrahedrally bonded silicon and aluminum are the building blocks for both the silicon 
nitride and SiAlON lattices and the oxynitride glasses. The cluster calculations revealed increasing strength of the tetrahedron bonds as oxygen is substituted for nitrogen, Table III. Also, the bonding was seen to be consistently greater in the Si-based tetrahedron for all O:N ratios as compared to the Al-based tetrahedron. However when the aluminum was highly coordinated with oxygen (e.g., $\mathrm{AlO}_{4}$ ), the binding energy rivaled that of the Sibased tetrahedra. Based on these calculations, one can suggest that breaking tetrahedral bonds at the interface would become increasingly more difficult as oxygen is substituted for nitrogen. Similarly, the presence of Al-O tetrahedra, especially with four oxygen, at the interface would promote the interface strength. These findings have now been supported by calculations involving two and three tetrahedron clusters that bridge the interface and involve both cation and anion substitutions. From this series of atomic cluster calculations, one can deduce that the formation of an epitaxial SiAlON layer leads to strong Si-0 and Al0 bonds in both directions across the interface. With continued substitution of $\mathrm{Al}$ and 0 into the SiAlON layer, the interface strength would be expected to increase based on these calculations which is consistent with decreasing critical debond angle seen in Table I.

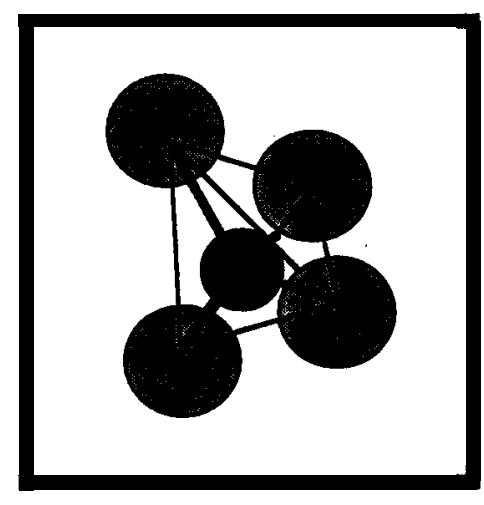

Figure 4. Atomic cluster calculations consider the effects of oxygen substitution on the binding energy of silicon (and aluminum) tetrahedrally coordinated with nitrogen.

Table III. Theoretical calculations reveal increase in binding energy body-centered $\mathrm{Si}$ tetrahedron as oxygen is substituted for nitrogen. Similar results are obtained for the binding energy Al body centered tetrahedron; however, these binding energies are consistently lower than the corresponding Si body-centered tetrahedron.

\begin{tabular}{|c|c|c|}
\hline Tetrahedron Configuration & \multicolumn{2}{|c|}{ Binding Energy (eV) within Tetrahedron } \\
\hline & $\mathrm{Me}=\mathrm{Si}$ & $\mathrm{Me}=\mathrm{Al}$ \\
\hline $\mathrm{MeN}_{4}$ & 11.6 & 8.7 \\
\hline $\mathrm{MeN}_{3} \mathrm{O}$ & 13.6 & 11.1 \\
\hline $\mathrm{MeN}_{2} \mathrm{O}_{2}$ & 16.0 & 12.5 \\
\hline $\mathrm{MeNO}_{3}$ & 18.1 & 14.3 \\
\hline $\mathrm{MeO4}$ & 20.2 & 15.1 \\
\hline
\end{tabular}




\section{Summary}

The fracture toughness and strength of self-reinforced silicon nitrides can be optimized by controlling the microstructural features. Incorporating beta seeds to control the size and number of elongated reinforcing grains has proven quite effective. Analyses of the crack bridging toughening mechanisms (e.g., frictional bridging and pull-out) show that increasing the diameter of the reinforcements can increase the toughness as the interfacial debond area where strain energy is dissipated by frictional processes increases. However when the grain aspect ratio and the debond length to grain length ratio remain constant, the models reveal very similar toughening effects are possible for a given volume fraction of either small or large diameter reinforcing grains. One the one hand, the debonded surface area per reinforcing grain over which frictional energy is dissipated decreases as the diameter decreases, and, at the same time, the number density of reinforcing grains increases. The results of the microstructural toughening models are consistent with experimental observations.

As noted, debonding of the interfaces associated with the elongated grains and the intergranular amorphous phase is a necessary step in the generation of bridging grains that serve to toughen the ceramic. Based on the present studies, the composition of the glass phase, as determined by the sintering aids, can play a key role in the interfacial debonding process. In the case of silicon oxynitride glasses containing yttrium and aluminum, the strength of the interfaces increases with decrease in the ratio of yttria to alumina in the additives. Thus the toughness is a function of the additive composition. The formation of a SiAION epitaxial layer on the reinforcing grains combined with an increase in the $\mathrm{Al}$ and 0 content of this layer result in stronger interfaces which limit interfacial debonding and the toughness. Atomic cluster calculations indicate the this increase in interface strength is associated with strengthening of the chemical bonding across the interface between the glass and grains. The interfacial strengthening effect being primarily a result of the replacement of $\mathrm{Si}-\mathrm{N}$ bonding by stronger $\mathrm{Si}-0$ bonds combined with $\mathrm{Al}-\mathrm{O}$ bonding along the interface.

Acknowledgments

Research sponsored by the U. S. Department of Energy, Office of Basic Energy Sciences, Division of Materials Sciences under contract DE-AC05-960R22464 with Lockheed Martin Energy Research Corp.

References

1. M. Savitz, Am. Ceram. Soc. Bulletin 78(1) 53-56 (1999).

2. K. Moerganthaler, private communication.

3. P. F. Becher, C. H. Hsueh, P. Angelini, and T. N. Tiegs, J. Am. Cerum. Soc. 71(12) 1050-1061 (1988).

4. P. F. Becher, J. Am. Ceram. Soc. 74(2) 255-69 (1991).

5. a. C. W. Li and J. Yamanis, Ceram. Eng. Sci. Proc., 10 (7-8) 632-45 (1989). b. T. Kawashima, H. Okamoto, H. Yamamoto, and A. Kitamura, J. Cerum. Soc. Japan, 99: 14, (1991). c. M. Mitomo, pp. 101-07 in Proc. Science of Engineering Ceramics, S. Kimura and K. Niihara, eds., Ceram. Soc. Jpn, Tokyo, 1991.

6. P. F. Becher, C. H. Hsueh, K. B. Alexander, and E. Y. Sun, J. Am. Cerum. Soc., 79(2) 298-304 (1996).

7. S. Kanzaki, K. Hirao, M. E. Brito, K. Watari, M. Toriyama, H. Imamura and M. Kitayama, "Development of High Performance $\mathrm{Si}_{3} \mathrm{~N}_{4}$ Through Textured Microstructure Control," presented at Am. Ceram. Soc. Annual Meeting, Cincinatti, OH, May, 1998. 
8. P. F. Becher, E. Y. Sun, K. P. Plucknett, K. B. Alexander, C-H Hsueh, H-T Lin, S. B. Waters, C. G. Westmoreland, E-S Kang, K. Hirao, and M. Brito, J. Am. Ceram. Soc., 81(11) 2821-30 (1998).

9. K. Hirao, T. Nagaoka, M. E. Brito, and S. Kanzaki, J. Am. Ceram. Soc. 77(7) 185762 (1994).

10. P. F. Becher, E. Y. Sun, C. H. Hsueh, K. B. Alexander, S. L. Hwang, S. B. Waters, and C. G. Westmoreland, Acta Muter., 44( 10) 388 1-93 (1996).

11. E. Y. Sun, P. F. Becher, C-H Hsueh, S. B. Waters, K. P. Plucknett, K. Hirao, and M. Brito, J. Am. Ceram. Soc., 81(11) 2831-40 (1998).

12. E. Y. Sun, P. F. Becher, C. H. Hsueh, G. S. Painter, S. B. Waters, S. L. Hwang, and M. J. Hoffmann, "Debonding Behavior Between $\beta-\mathrm{Si}_{3} \mathrm{~N}_{4}$ Whiskers and Oxynitride Glasses With or Without an Epitaxial $\beta$-SiAlON Interfacial Layer," Acta Mater., in press.

13. I. Tanaka, K. Niihara, S. Nasu, and H. Adachi, J. Am. Ceram. Soc., 76( 11) 2833-38 (1993).

14. P. Dudesek and L. Benco, J. Am. Ceram. Soc., 8 1(5) 1248-54 (1998).

15. G. S. Painter, ORNL, private communications. 